differentiation of primordia appears to continue at a higher rate than does the rate of division and expansion of cells leading to growth of a leaf. The stage of growth is also important ; following a temperature check, a higher relative growth-rate of leaves occurs if some leaves have expanded than if no leaves are present. The influence of conditions at germination persists long into the growing period. Prof. G. E. Blackman (University of Oxford) discussed the effects of light and temperature on leaf growth. These vary with the species: reduction of light intensity below full spring and summer daylight may have little effect on the leaf area of one group of plants ; in another group, there may be a large increase in leaf surface with reduced light almost to the compensation point ; whereas in a third the effect may be intermediate. There is, in general, a direct curvilinear relation of net assimilation-rate and an inverse relation of the leaf area ratio with light intensity; the resultant effect on relative growthrate, being the product of these terms, depends on the magnitudes of the responses involved in these two relations. The retarding effect of increasing light on leaf expansion occurs with intensities greater than 300-600 ft.-candles; at lower intensities there is a positive effect. Leaf area increases with temperature up to about $25^{\circ} \mathrm{C}$., but interactions occur between different levels of temperature and light. Dr. H. L. Penman (Rothamsted Experimental Station) showed that the growth of grass is closely proportional to the total energy supplied at the surface, and also to the potential transpiration. Water becomes limiting at small values of soil moisture deficit; these values are smaller with low than with high nitrogen supply. The slope of the curve relating growth to incoming radiation is also influenced by the nitrogen-level. Dr. D. J. Watson (Rothamsted Experimental Station) emphasized the general conclusion that the variation in dry-weight yield per acre is determined mainly by leaf growth. Variations in the rate of photosynthesis have little influence. The maintenance of dense leaf coverage during the major portion of the growth poriod provides the main possibility of increasing yield. There is a limit, however, to the increase in returns possible, as mutual shading of leaves ultimately reduces the net assimilation-rate sufficiently to offset the gain from the larger leaf surface. Yield of grain depends largely on a large leaf area during grain formation.

The points raised in the papers were vigorously discussed, and some of the conclusions and techniques used were demonstrated. Full proceedings will be published elsewhere. F. L. MiLthorpe

\section{FRESHWATER BIOLOGY IN SCOTLAND}

T HE symposium during April 9-10 on freshwater biology in Scotland, arranged by the Institute of Biology (Scottish Branch), was the first occasion when a comprehensive survey of the progress of work on Scottish fresh waters has been presented. This being so, it is natural that it should cover a wide diversity of subjects. Subjects which ranged from the effects of hydroelectric schemes on migratory fish to the emergence of aquatic insects were submitted for discussion by speakers from the Universities of Edinburgh and Glasgow, the Brown Trout Research Laboratory, Pitlochry, the Oceanographic Labor- atory, Leith, and the North of Scotland Hydroelectric Board. The topics brought forward for discussion in the first two sessions were not unrelated, and most can be fitted into a sequence commencing with conditions for life in Highland waters and passing to ecological aspects of the flora and fauna.

It was reported that streams of the catchment areas of Highland lakes and rivers are markedly subject to excessively rapid run-off, partly due to the removal of vegetation by clearing of timber and the burning of moors and partly also to extensive channel draining of sheep pastures. When peat is exposed it is not as efficient a water store as might be supposed. Rainfall reduces the surface layer to a colloidal gel, which inhibits deeper penetration and enhances rapid surface drainage into water-courses, which, in their upper reaches, usually flow down steep slopes. The result is extensive erosion in the lower reaches under storm conditions. Rapid drainage and influx of peat derivatives into Scottish lakes are contributory to the main cause, the mineralogical nature of the Highlands, of the paucity of plant nutrients in these waters. More than half those studied have a calcium content (expressed as $\mathrm{CaCO}_{3}$ ) of less than 10 p.p.m. and nearly all have less than 50 p.p.m. They have not evolved to a degree of eutrophy permitting the reversible oxidation-reduction process described by $\mathrm{Ohl}^{1}$ and Mortimer ${ }^{2}$, with the result that plant nutrients tend to be occluded in the bottom muds and their main source lies in the small amounts brought in by inflowing streams.

Studies on phytoplankton in Scottish lakes, especially the application of Nygaard's ${ }^{3}$ 'compound quotient' to a general survey, emphasize the oligotrophic nature of the majority. This quotient, which is the number of species characteristic of eutrophic waters (for example, species of Chlorococcales and Myxophyceae) divided by the number of species characteristic of oligotrophic waters (for example, species of Desmidaceae), displays a correlation with chemical evidence and with productivity of bottom fauna. Where past records exist, it has been possible to demonstrate the rate of evolution of a lake. Loch Leven, in Fife, with a quotient of 2 , fifty years ago ranked as mesotrophic. To-day, with a quotient of 8 , it is eutrophic. Loch Lomond, on the other hand, has shown no change over the same period.

Known in England only in the Lake District, the cladoceran crustacean, Holopedium gibberum, is absent from eutrophic waters but abundant in many oligotrophic lakes in Scotland. The conditions governing its distribution are not yet fully understood, for it is absent from some water bodies which appear to be closely similar to those in which it does occur. A possible clue to the uneven distribution is the presence of a certain minimum amount of dissolved organic material in the water.

The impermanence of fresh waters was discussed from another aspect, that of their invasion by pulmonate gastropods. It was suggested that the co-existence of pulmonates with a wide range of adaptations, from the great phenotypic plasticity and high ratio of selection-that is, number of individuals surviving to breed annually-of Lymnaea peregra to the great genotypic specialization and low ratio of selection of Ancylus fuviatilis, may be credited to the instability of freshwater habitats relative to their marine counterparts.

In papers on freshwater fishes and their parasites, during the second day of the meeting, interest lay in new or little-known occurrences in Scotland. Among 
endoparasites of fishes, the strigeid trematode, Cotylurus erraticus, was reported to form massive metacercarial infestations around the heart of powan, Coregonus clupeoides; with an incidence of 100 per cent in Loch Lomond but apparently absent from these fish in Loch Eck, their only other habitat. Present also in trout from Lochs Lomond and Leven, Cotylurus does not attain in them the same high infestation. This difference in degree of infestation may be related to differing habits of the hosts, in that trout are fluviatile for at least their first year, whereas Coregonus spends its whole life in the lake.

The pseudophyllidean cestode, Triaenophorus nodulosus, occurs in pike in Loch Lomond, and its finding constitutes the second record for Britain. Since plerocercoids of this species have been found only in yearling pike, it would appear that the lifecycle is dependent on cannibalism. Apart from the consideration of their parasites, pilke were shown to have a phase in development which is probably the retention of an archaic actinopterygian characteristic. The embryos hatch when the branchial region, pectoral fins and mouth are still imperfectly developed and, for a period of about ten days, hang suspended from water plants. They are attached to the support by the secretion of two cement glands placed in front of the eyes.

An addition to the Scottish fauna was established among the fishes. A biometrical study of char, Salvelinus alpinus, recently discovered in Loch Eck, Argyll, yielded results which give this fish the rank of a distinct sub-species.

${ }^{1}$ Ohle, W., Naturwiss., 25, 3 (1937).

${ }^{2}$ Mortimer, C. H., J. Ecol., 29 (2), 49 (1941). ${ }^{3}$ Nygaard, G., Kon. Danske Videnskabernes Selskab., Biol. Skr., 7 (1)
293 (1949).

\section{CHEMISTRY OF OXYGENATED HETEROCYCLIC COMPOUNDS}

\section{INTERNATIONAL COLLOQUIUM AT LYONS}

$\mathrm{L}$

ESS than two months after the Dublin sym. posium on naturally occurring pyrones (see Nature, 176,637 ; 1955), a similar meeting devoted more particularly to naturally occurring flavonoid compounds, was held in Lyons during September 5-10. Twenty-six scientists from ten different countries took part in these discussions, during which the different aspects of the chemistry of oxygenated heterocyclics were reviewed.

The first series of reports were in the field of organic chemistry. M. Mousseron (Montpellier) discussed the reactions of epoxides in relation to their steric structure. He suggested a new method for their quantitative estimation in the presence of $-\mathrm{SCN}$ ions. The fixation of water by epoxy-1:2 cycloalkanes was discussed. The epoxide structure occurs in the transition states of many reactions and leads to compounds having a trans configuration.

G. Sandris and G. Ourisson (Paris) discussed the synthesis and properties of $2: 2: 5: 5$-tetramethyltetrahydrofuran. Mention was made of the effect, on the spectral properties of this type of compound, of replacement of the heterocyclic oxygen by methylene. In some cases, for example, when there was an $\alpha$-diketonic group in the 3- or 4-position, the authors achieved a molecular rearrangement to a four. membered ring (trimethylene oxide).
The chemistry of coumarins in general was reviewed by N. P. Buu-Hoï (Paris). The most reactive position in coumarone is the 2-position, while in thionaphthene it is at the 3-carbon. A molecule like brasane is far less reactive than the analogous polycyclic hydrocarbon (naphthacene).

C. Mentzer (Lyons) gave an account of the synthetic methods leading to benzopyrone compounds (coumarins, chromones, flavones and their derivatives). The methods were classified according to linkages formed. The condensation of an aromatic $\mathrm{C}_{6}$ group with $\mathrm{C}_{3}$ molecules was discussed in detail. $\mathrm{A}$ complete list of coumarins, chromones and flavanones, obtained by the author and his collaborators by the 'thermal condensation' of phenols with malonic or $\beta$-ketonic esters, was given.

A. Dreiding (Zurich) has synthesized 5:6:7:8-tetrahydrocoumarin by a Reformatsky reaction between ethyl monobromacetate and 2-(hydroxymethylene)cyclohexanone. It may be possible to apply this method to the synthesis of other $\alpha$-pyrones starting from $\beta$-dicarbonyl derivatives.

In a second series of papers, the oxygenated heterocyclics were discussed with emphasis on the biochemical aspects. As in the Dublin symposium, the flavones and their derivatives, as well as other less well-known lactones, were the focus of attention.

T. R. Seshadri (Delhi) showed the possibility of the in vitro transformation of flavanones into dihydroflavonols by the addition of an oxygen atom to the 3-position. This can be achieved : (a) by bromination or iodination of the acetyl derivative of the flavanone and subsequent treatment with silver acetate; $(b)$ by the action of lead tetra-acetate; (c) by the action of Fenton's reagent (hydrogen peroxide + ferrous ion) on the acetyl derivatives.

T. S. Wheeler and E. M. Philbin (Dublin) discussed molecular rearrangements in the flavonoid field. The Wessely-Moser rearrangement has been extended to chromanols and dihydroxyxanthones. A new type of rearrangement was described in which the 2-aryl nucleus takes the place of the second benzene nucleus in the flavone molecule.

The chemistry of natural aurones was reviewed by T. A. Geissman (Los Angeles). These substances (benzal-2-coumaranones) occur in many higher plants of the genera Cosmos, Coreopsis, etc. The author, who recalled the work of Marini-Bettolo, Hattori and others, has studied their synthesis, properties, detection in plants, isolation and spectral properties in relation to structure.

S. Hattori and M. Shimokoriyma (Tokyo) presented two reports, one dealing with flavonic glycosides from the leaves of Calystegia japonica and hederacea, the other on the localization of the flavonoid pigments in 'Cosmos sulphureus'. It is interesting to note that Calystegia japonica Choisy (Convolvulaceae) contains a rhamnoglucoside of kæmpferol, in which the disaccharide unit located in position 3 has been identified as rutinose, while Calystegia hederacea, a species so similar as to be easily mistaken for the former, contains kæmpferol 3 -galactoside identical with trifolin from the flowers of Trifolium repens.

Dihydroflavonols were discussed by J. Gripenberg (Helsinki). These compounds are of interest because of the manner in which they become rearranged in alkaline media. In contrast to what happens in aurones, the rearrangements of dihydroflavonols are accompanied by contraction of the heterocyclic ring. 